\title{
THEORETICAL INVESTIGATION OF TRAFFIC EQUILIBRIUM ON BRIDGES
}

\author{
Zsuzsanna Bede \\ Budapest University of Technology and Economics \\ Department of Transport Automation \\ H1111, Budapest, Muegyetem rkp 3 \\ E-mail: bede.zsuzsanna@mail.bme.hu
}

Adam Torok

Budapest University of Technology and Economics

Department of Transport Economics

H-1111, Budapest, Muegyetem rkp. 3

E-mail:atorok@kgazd.bme.hu

\begin{abstract}
Road traffic flows on a straight road segment such as bridges are modelled in this article. The mathematical model of traffic flows has been constructed by using the method of lumped parameters. Changeable lane direction and road pricing has been theoretically investigated in order to understand the shifting in supply and/or demand curves of traffic participants in equilibrium. The article presents assumptions for constructing the mathematical model. Demand can be influenced by road pricing, in its turn, supply can be influenced by extension of infrastructure with reversible lanes.
\end{abstract}

Keywords: traffic flow, mathematical modelling, supply and demand curve, bridges

\section{Introduction}

Road transport is one of the main inland transport modes providing door-to-door services for people all over the world. Each inland territory is criss-crossed by interurban road and street network. Vehicle flows carry people, distribute industrial freight and work equipment on these network elements (Szendrö, 2010). In some cases, the variability of landscape may require additional infrastructural elements, such as bridges, to be built. Road pricing is an economic concept regarding the various direct charges applied for the use of roads. The road charges in this case include tolls and congestion charges, which may vary by time or by vehicle type (Gehlert et al., 2008). Road pricing has two distinct objectives: revenue generation, usually for road infrastructure financing, and congestion pricing for demand management purposes. Road pricing could be one tool of sustainable development, of sustainable transportation that could efficiently satisfy the needs of the future (Csete, 2006). In this paper, authors are only investigating price as a traffic controlling parameter. For the purposes of this article, externalities are considered to be a part of the pricing regime. The majority of road vehicles that are running on road elements and bridges are driven by internal combustion engines; therefore, besides practical use they also create a lot of problems, such as air pollution with combustion products and particulate matter, noise, vibration, utilization of used oil and other materials, recycling of cars and their parts. Cars consume a lot of energy; therefore when optimising traffic flows, a lot of wide-range problems are solved or balanced, from vehicle manufacturing to their utilization.

\section{Methodology}

A lot of burning problems arise when cars are used and here the main problems to be solved by both engineers and scientists are pollution reduction (through engineering or by driving less - changing behaviour) and energy saving. Various problems caused by vehicles are discussed in the article written by Makaras et al. (2011). These authors discuss vehicle dynamics in the flow, fuel consumption, the impact of dynamics of cars on the environment, touch upon the driver's model and various driving styles. Torok (Barabas \& Todorut, 2011) investigated the dynamics of $\mathrm{CO}_{2}$ emission reductions with increasing biofuel blends. Szendrö et al. (2012) investigated the adoption possibilities on the local level. Janulevičius et al. (2010) 
presented the methodology of determining energy consumption taking into account engine capacity and specific fuel consumption. Wu and Liu (Wu \& Liu, 2011) presented in their article the methodology of calculating fuel consumption by taking into account such criteria as aerodynamics and rolling resistances. The fuel consumption model was constructed based on the neural network theory. Smit et al. (2008) present and generalize three emission models, where the impact of congestion on motor vehicle emissions is evaluated differently and present indicators to identify transport congestion. The article also presents congestion identification models. Jovic \& Doric (2010) used the programming package PTV Visio to model traffic flows on the urban street network and based on that present vehicle emissions. Jakimavičius \& Burinskiene (2010) investigated vehicle flow optimization methods and their application possibilities when informing traffic users about the situation in the city. Péter and Bede (Bede et al., 2010)] analysed the optimal control in modelling of Reversible Lane System (RLS). The function of every element and the contacts between the elements can cease in case of direction change in any part of the network, and then new contacts and new functional elements are activated. The availability of the RLS was examined in a sample network depending on the traffic density, using a new principle, which responds to the dynamic change of the structure of the network graph (Peter \& Bokor, 2011; Bede \& Péter, 2014).

This article gives an example of applying mathematical models of traffic flows to simulate change in traffic flow condition when the supply and demand curves are shifted by changes in road pricing (due to changes in traffic flow or internalising external effects of road transport) or changes in lane direction (Bede \& Péter, 2012), respecting road safety (Figure 1).
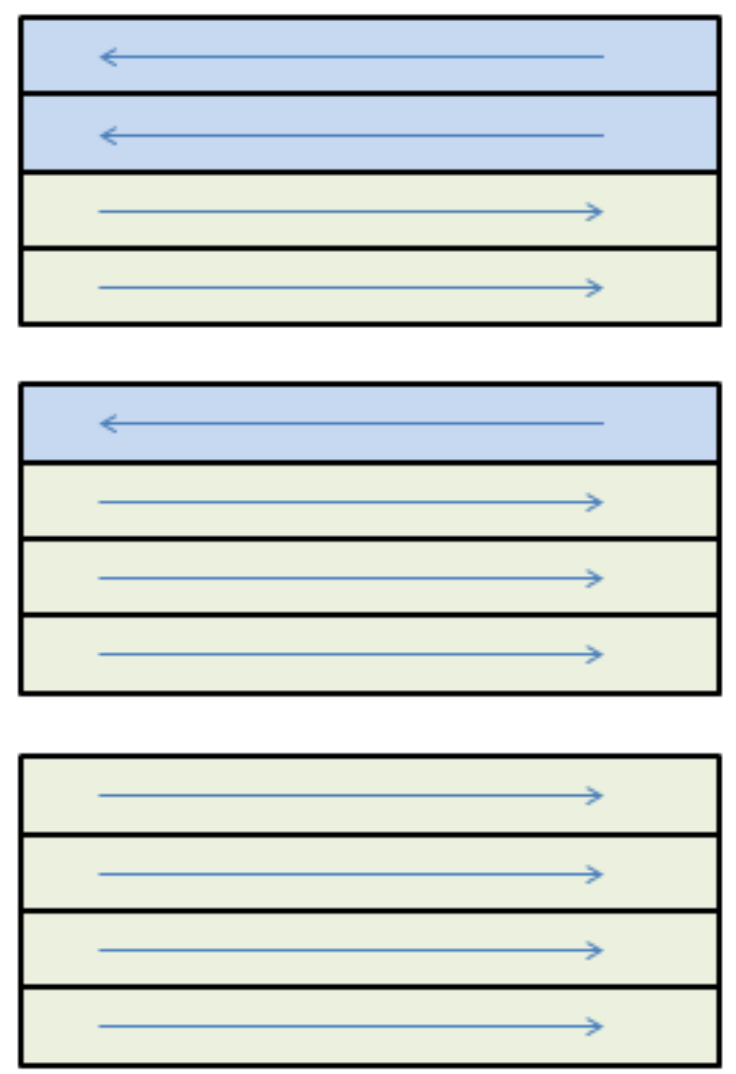

Figure 1. Possibilties of lane direction changing (Source: autors' compilation)

When describing traffic flows, a traffic lane is used as a keyword. An assumption is made that cars cannot drive on an opposite traffic lane; therefore, the road is split into separate and competing traffic lanes in a system that very much resembles competing products on the same perfect market. Two-way roads are described in the mathematical model as separate one-way roads with one or several traffic lanes (Bede \& Péter, 2012). In this model, a traffic lane segment is taken as a finite-length line, which is divided into equal segments the length of which is $L$ (Figure 2). 


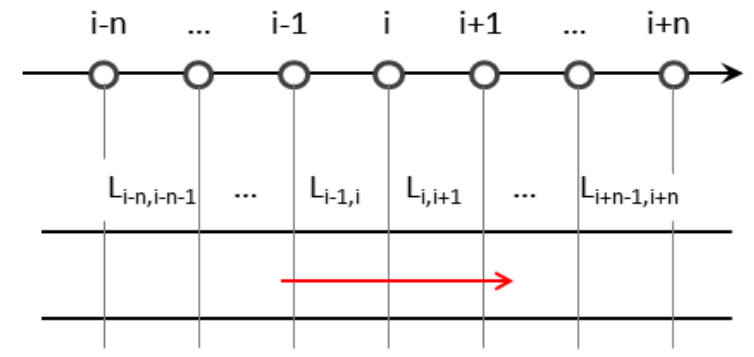

Figure 2. Transport flow model on a straight segment of a traffic lane (Source: Junevičius et al., 2011)

The parameters of a road segment (traffic flow speed, traffic flow concentration or traffic flow intensity) can be measured at the end points. The point, which connects two adjacent segments, has a point common to both segments. Minimal and maximal values of traffic flow parameters for each road segment are set separately and may be different. Minimal values of traffic flow speed and concentration are usually equal to zero. Maximum possible speed is based on observations. Maximal permitted traffic flow concentration value may be calculated according to the following formula (1):

$k=\frac{n_{\text {auto }}}{L_{i, i+1}}$

where

$n_{\text {auto }}$ - number of vehicles in segment (units),

$L_{\mathrm{i}, \mathrm{i}+1 .}$ - road segment length $(\mathrm{m})$.

Let us suppose that a road segment cannot be overfilled. If the number of vehicles on a road segment reaches an upper boundary limit, more vehicles cannot enter this road segment. If a road segment is full, the value of vehicles ' flow remains the same, increases or slightly decreases, but is insufficient and the road segment ahead remains overfilled, vehicles start accumulating on the road segment subsequent to the full road segment. Vehicle flow speed is limited as well. Each road segment has its own speed limit, which can differ.

Traffic lane segments split in the model are numbered $L_{i-1, i}, L_{i+1, i}$ when $i=1 \ldots n, i-$ road point number (Figure 3).

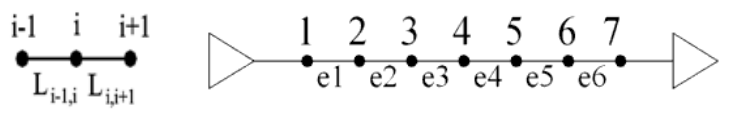

Figure 3. Description of elements of a straight road. a) two elements $L_{i-1, i}$ and $L_{i+1, i}$, are connected at point $i$; b) a straight road segment drawn from several road segments connected at points $1 \ldots 7$

(Source: Junevičius et al., 2011)

The first point of an element is equal to the last point of the preceding element, and the last point of an element is equal to the first point of the subsequent element (Junevičius et al., 2011). It is very important that no traffic can be added in the segment except at the beginning and end point. This theory provides advantages in using bridge pricing in order to reach optimal traffic flow.

\section{Results}

Different competing lanes have been investigated by the authors. Authors have assumed that not only the price of lanes but direction is also changeable. In a macro economical sense, those one-way lanes are competing with the other direction. In this case authors have investigated the very simple model of RLS in case of a bridge. Within these circumstances the optimizing this has to be decided between tolls level on the bridge and direction of the lanes in order to maximalize the revenues (3): 
$R E V=\sum_{i=1}^{n}\left(k_{i} \cdot L_{i} \cdot p_{i}\right)$

where

$k_{\mathrm{i}}$ - the number of vehicles in segment ( PCU/m),

$L_{\mathrm{i} .}-$ road segment length $(\mathrm{m})$

$p_{i}-$ toll fee $(€ /$ PCU)

In this article authors tried to build up a model of competing RLS in a bridge. Authors have assumed that competing RLS is behaving like a set of competing goods, therefore the basic macroeconomical assumptions and rules were used. Practical uses of supply and demand analysis often centred around the different variables that change equilibrium price and quantity, represented as shifts in the respective curves (Figure 4). Comparative statistics of such a shift traces the effects from the initial equilibrium to the new equilibrium.

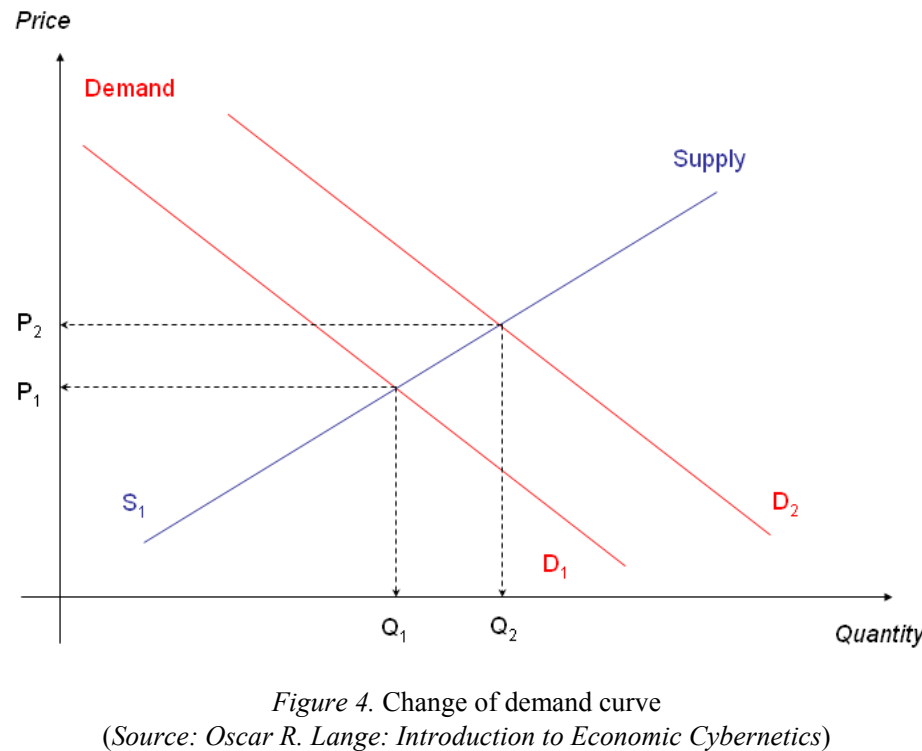

Authors have simulated an unwanted rightward shift in demand, increasing equilibrium quantity that increases price. At each price point, a greater quantity is demanded, as from the initial curve $\mathrm{D}_{1}$ to the new curve $\mathrm{D}_{2}$ (more and more people wanting to pass the bridge, for example). In the diagram, this raises the equilibrium price from $\mathrm{P}_{1}$ to the higher $\mathrm{P}_{2}$ in order to keep the balance and to control traffic flow. This raises the equilibrium quantity from $\mathrm{Q}_{1}$ to the higher $\mathrm{Q}_{2}$. Mathematically a linearised demand function can be described as (4):

$x_{t}=a \cdot p_{t}+\alpha$.

In the example above, there has been an increase in demand, which has caused an increase in (equilibrium) quantity. The increase in demand could also come from changes in the value of travel time. People sitting in congestion could pay higher fee for the bridge. This would cause the entire demand curve to shift, changing equilibrium price and quantity. The equilibrium quantity, price and demand are different from the previous balanced point. At each point, a greater amount is demanded (when there is a shift from $\mathrm{D}_{1}$ to $\mathrm{D}_{2}$ ).

The increased demand led to increased profit that, in turn, could shift the supply curve (Figure 5). For example, assume that some of the lanes on the bridge can be turned over - the direction can be changed (see Figure 1). 


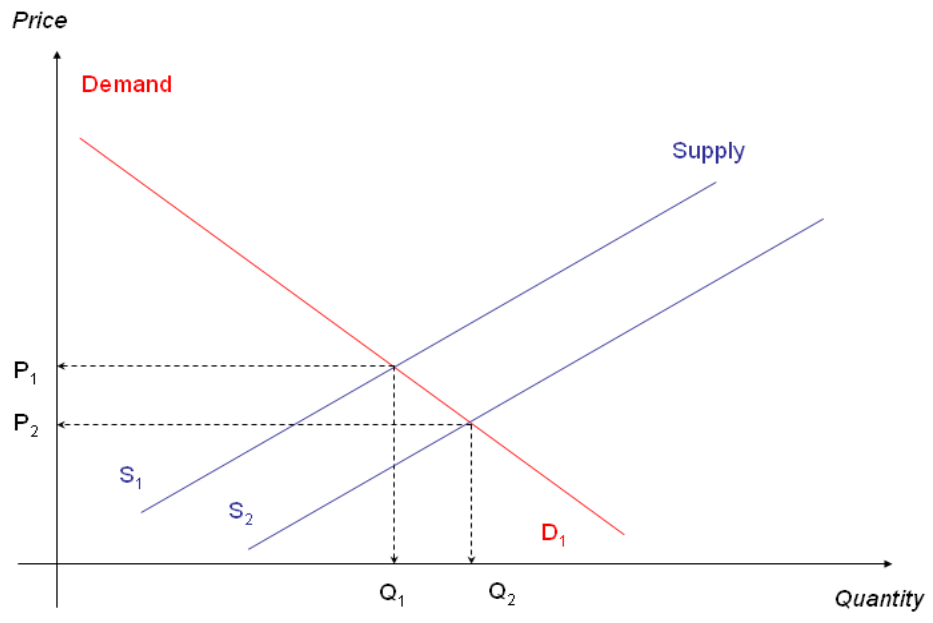

Figure 5. Change in the curve of supply

(Source: Oscar R. Lange: Introduction to Economic Cybernetics)

To put it another way, drivers will be able to use more lanes at every price and this shifts the supply curve from $S_{1}$ outward, to $S_{2}$ - an increase in supply. This increase in supply causes the equilibrium price to decrease from $P_{1}$ to $P_{2}$. The equilibrium quantity increases from $Q_{1}$ to $Q_{2}$ as the quantity demanded increases at the new lower prices. In a supply curve shift, the price and the quantity move in opposite directions. Mathematically the linearised supply function can be described as

$y_{t}=\beta+b \cdot p_{t-1}$.

It is well known that market equilibrium is when demand $x_{t}$ and supply $y_{t}$ are equal. For every time period $t$ there is an equilibrium that can be described with

$a \cdot p_{t}+\alpha=b \cdot p_{t-1}+\beta$

$a \cdot p_{t}=b \cdot p_{t-1}+(\beta-\alpha)$,

where

$x_{t}=a \cdot p_{t}+\alpha$, as demand function

$y_{t}=b \cdot p_{t-1}+\beta$, as supply function

$p_{t}-$ price in time $t$

market equilibrium is reached when $p_{t}=p_{t-1}$. Therefore

$\hat{p}=\frac{\beta-\alpha}{a-b}$

and the actual price differs from the market equilibrium price with

$\tilde{p}=p_{t}-\hat{p}=p_{t}-\frac{\beta-\alpha}{a-b}$.

At this time the market equilibrium can be described as:

$a \cdot \tilde{p}_{t}=b \cdot \tilde{p}_{t-1}$

$\widetilde{p}_{t}=\frac{b}{a} \cdot \widetilde{p}_{t-1}$ 
With the above-mentioned model (Figure 6) authors have tried to analyse the effects of changing lane direction on bridge tolling as a form of pricing method. Theoretical investigation shows that if it is technically possible to change lane direction (as extension of infrastructure) then such an action could lead to decreased prices.

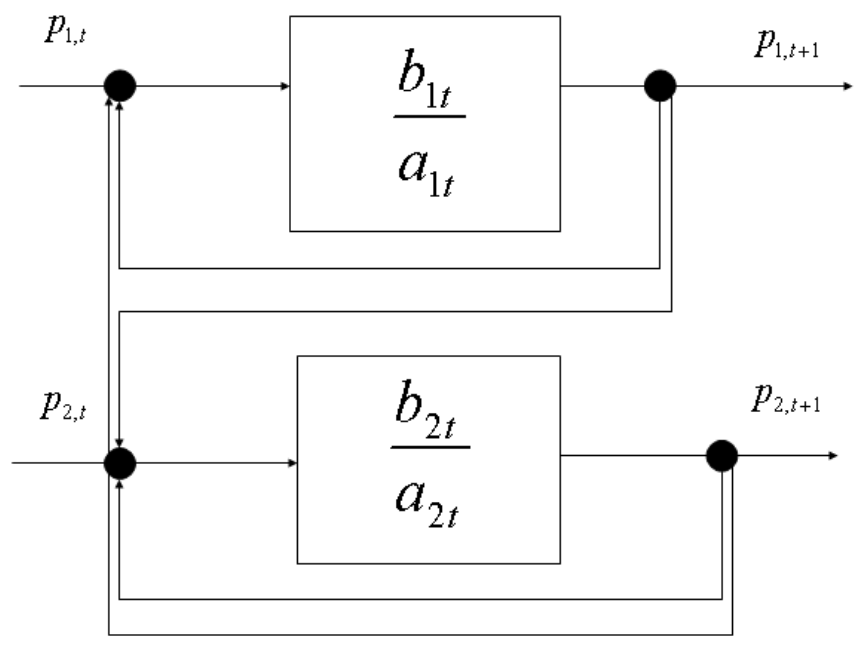

Figure 6. Cybernetic model of market equilibrium with two concurring group of lanes. (Source: Oscar R. Lange: Introduction to Economic Cybernetics, own research)

\section{Analysis and Discussion}

The above-explained model can be extended by marginal social cost-based road pricing. In that case bridge tolling is not only a tool for controlling traffic flows, but to make users pay the cost of their externalities. In such a system, externalities can be estimated and be internalised in the pricing regime.

As Figure 6 shows, if a pricing regime controls the traffic flow then social marginal cost-based pricing can cause an unwanted shift in the balanced equilibrium point. Revenues cannot only be maximised through proper pricing but in some cases proper layout provides an opportunity to change lane direction. Keeping road safety in mind, more revenue can be generated with the use of variable lane direction.

\section{Acknowledgements}

The contribution of anonymous reviewers is gratefully acknowledged. This work is connected to the scientific program of the "Development of Quality Oriented and Harmonized $R+D+I$ Strategy and Functional Model at BME" project. These projects are supported by the New Szecheny i Development Plan (Project ID: TAMOP-4.2.1/B-09/1/KMR-2010-0002) and "Modelling and Multi-Objective Optimization Based Control of Road Traffic Flow Considering Social and Economical Aspects" program CNK 78168 of OTKA. The authors are grateful to the support of Bólyai János Research fellowship of HAS (Hungarian Academy of Science).

\section{References}

1. Szendrő, Gábor. (2010). Sustainable biofuels in Hungary and Europe - self-defeating incentives? Scientific Journal on Agricultural Economics, 54(24), 71-78.

2. Gehlert, T., Nielsen, O., Rich, J., Schlag, B. (2008). Public acceptability change of urban road pricing schemes. Proceeding of the institution of civil engineers - transport, 161(3), 111-121.

3. Csete, M. (2006). Local realization of sustainability. Scientific Journal on Agricultural Economics, 50(1), 62-69.

4. Makaras, R., Sapragonas, J., Kersys, A., Pukalskas, S. (2011). Dynamic model of a vehicle moving in the urban area. Transport, 26(1), 35-42. DOI: 10.3846/16484142.2011.558630. 
5. Barabas, I., Todorut, I.A. (2011). Predicting the temperature dependent viscosity of biodiesel-dieselbioethanol blends. Energy \& Fuels, 15(12), 5767-5774. DOI: 10.1021/ef2007936.

6. Szendrő, G., Csete, M., Török, Á. (2012). Unbridgeable gap between transport policy and practice in Hungary. Journal of Environmental Engineering and Landscape Management, 20(2), 104-109. DOI: $10.3846 / 16486897.2012 .660881$.

7. Janulevičius, A., Juostas A., Pupinis, G. (2010). Engine Working Modes During Tractors Operational Period. Mechanika, 3(83), 58-63.

8. Wu, J., Liu, J. (2011). Development of a Predictive System For Car Fuel Consumption Using an Artificial Neural Network, Expert Systems with Application 38(5): 4967-4971, DOI: 10.1016/j.eswa.2010.09.155.

9. Smit, R.; Brown, A.L., Chan, Y.C. (2008). Do Air Pollution Emissions and Fuel Consumption models for Roadways Include the Effects of Congestion in the Roadway Traffic Flow? Environmental Modelling \& Software, 23(10-11), 1262-1270. DOI: 10.1016/j.envsoft.2008.03.001.

10. Jovic, J., Doric, V. (2010). Traffic and Environmental Street Network Modelling: Belgrade Case Study. Transport, 25(2), 155-162. DOI: 10.3846/transport.2010.19

11. Jakimavičius, M., Burinskienè, M. (2010). Route Planning Methodology of an Advanced Traveler Information System in Vilnius City. Transport, 25(2), 171-177. DOI: 10.3846/transport.2010.21

12. Bede, Zs., Szabó, G., Péter, T. (2010). Optimalization of Road Traffic With the Employment of Reversible Direction Lanes. Periodica Polytechnica, 38(1), 3-8. DOI: 10.3311/pp.tr.2010-1.01.

13. Peter, T., Bokor, J. (2011). New road traffic networks models for control. GSTF International Journal on Computing, 1(2), 227-232. DOI: 10.5176_2010-2283_1.2.65.

14. Bede, Zs, Péter, T. (2014). Optimal control with the dynamic change of the structure of the road network. Transport, 29(1), 36-42.

15. Bede, Zsuzsanna, Péter, Tamás. (2012). The mathematical modeling of Reversible Lane System. Periodica Polytechnica-Transportation Engineering, 39(1), 7-10.

16. Bede, Zsuzsanna, Péter, Tamás. (2012). The development of large traffic network model. Periodica Polytechnica-Transportation Engineering, 39(1), 3-5.

17. Junevičius, R., Bogdevičius, M., Török, Á. (2011). Modelling of internal combustion engines' emission through the use of traffic flow mathematical models. Transport, 26(3), 271-278. DOI: $10.3846 / 16484142.2011 .621978$. 